\title{
A influência da canonicidade de linking sintático-semântico na construção do significado
}

\author{
Marília de Carvalho Caetano Oliveira \\ $\mathrm{FFCL/Congonhas}$ \\ FFCL/Santa Rita
}

\section{Abstract}

The aim of this work was to investigate to what extent the canonical correspondence (canonical linking) between the syntactic structure and thematic roles of the direct objects, subjects and prepositional phrases affect the construction of meanings of the texts. In a second level of analysis, the effects of canonical linking were investigated in interaction with processing capacity and prior knowledge.

Firstly, two preliminary tests were applied: a test of span reading to classify the readers according to high, middle and low processing capacity and a test to measure the reader's prior knowledge about the texts (the functioning of a washing machine and the functioning of a scanner).

The results revealed that canonical linking, isolated or in interaction with the other two factors, have a systematic effect; however, its effects are diversified in the comprehension of the direct objects, subjects and prepositional phrases.

These results suggest, among other things, the existence of similarities and differences in the processing of these sentence constituents. A major symmetry in the processing of the direct objects and subjects in comparison with prepositioned phrases was observed. 


\section{INTRODUÇÃO}

U

ma das maiores polêmicas com relação ao ensino de Língua Portuguesa na educação atual enfoca questões referentes à leitura. Talvez a grande falha do ensino de interpretação de textos nas escolas esteja em analisar o produto desvinculado do processo (leitura propriamente dita). Se a escola apenas se preocupa com os aspectos observáveis da leitura (entonação, por exemplo), ela desconsidera todo o processamento psicológico por que os alunos passam até chegarem ao produto final da leitura. Por isso, se o professor souber maiores detalhes sobre as partes que compõem o processo de leitura, mais específicos serão seus objetivos ao propor determinada atividade didática.

\section{FUNDAMENTAÇÃO TEÓRICA}

A visão científica da leitura tem evoluído de um processo passivo de recepção da mensagem de um texto (extração de significados) para um processo complexo, ativo, uma atividade de construção que se desenvolve por subpartes ou etapas.

\subsection{Modelo de processamento na leitura}

Considerando a mente como um sistema organizado, FODOR (1983) propõe que a mente é como um sistema computacional, com sistemas de input separados (módulos) para a visão, audição e linguagem, e um sistema de processamento central.

Os sistemas de input são responsáveis pelo processamento dos estímulos externos ao organismo, que são captados pelos órgãos perceptuais como a visão e a audição, processam os estímulos de forma rápida e restrita e têm por função alimentar o processador cognitivo central com as informações do mundo exterior. 
Por sua vez, o sistema central (ou sistema cognitivo central) parece ser, em grande parte, volitivo. Nele são recebidas e processadas as informações proposicionais (conceituais) vindas do módulo lingüístico e da interface (a interface aqui é entendida como o contato entre os processos que são automáticos e os que não são automáticos). Assim sendo, a Modularidade defende uma distinção entre percepção e cognição, em que se distinguem os processos automáticos dos processos voluntários.

\subsubsection{Domínios de processamento na leitura}

O processo de leitura envolve não somente a decodificação de sinais gráficos em sons, mas, principalmente, a interpretação desses sinais. A partir desse pressuposto, assume-se que a decodificação é feita nos domínios de processamento do módulo e a interpretação se desenvolve nos domínios do processador cognitivo central.

Tanto o módulo lingüístico como o processador cognitivo central apresentam subprocessos que são responsáveis pelo processamento de informações específicas, e esses subprocessos seriam: acesso lexical (reconhecimento de palavras), processamento de relações sintáticas, elaboração de proposições (conceitos), produção de inferências (ativação de informações não-explícitas), construção de esquemas (estruturas do conhecimento prévio) e integração de conhecimentos (integração textual com o conhecimento prévio do leitor).

Nesta pesquisa optou-se pela investigação do subprocesso referente à elaboração de proposições.

\subsection{O objeto de estudo: a elaboração de proposições}

Os vocábulos podem articular-se tanto no nível sintático como no semântico (além de outros níveis, com o fonológico, etc). Sendo assim, um dos focos de interesse desta pesquisa é justamente a relação existente entre os níveis sintático e semântico e, para isso, torna-se necessária a utilização de arcabouços teóricos que dêem respaldo a ambos os níveis. 
Inicialmente, considera-se a descrição sintática aqui utilizada, ou seja, a teoria sintática que permeia as classificações dos elementos formais das frases analisadas (nessa pesquisa, foi dado enfoque ao processamento do sujeito, objeto direto e sintagma preposicionado).

PERINI (1996) postula que a definição formal da função de sujeito refere-se ao "termo da oração que está em relação de concordância com o núcleo do predicado" (verbo). Como exemplo (grifado), pode-se citar a oração o médico coleta informações.

A outra função sintática aqui realçada é o objeto direto. O autor propõe a definição formal de objeto direto através da atribuição de traços que seriam [-CV, +Ant, +Q, -CN]. À sigla [CV] corresponde a propriedade de estar em relação de concordância com o núcleo do predicado, [Ant] corresponde à propriedade de poder aparecer no início da oração em uma frase correspondente, [Q] corresponde à propriedade de poder ser retomado pelos elementos que, o que ou quem e o traço $[\mathrm{CN}]$ diz respeito à propriedade de estar em relação e concordância (nominal) com outro termo da oração. Para exemplificar o objeto direto (grifado), tem-se a frase os médicos examinaram apaciente inconformados.

Ao conceituar o sintagma preposicionado, OUHALLA (1994) sugere que sua formação inclui um verbo cujo complemento consiste em uma preposição e um sintagma nominal. O exemplo (grifado) a seguir retrata este constituinte: a garota bateu naporta.

Com relação à análise semântica das frases, considera-se um arcabouço teórico que busca explicar como os conceitos se relacionam para formar as proposições. A seguir, sugerem-se alguns dos fatores que talvez desempenhem um papel importante na elaboração de proposições.

\subsubsection{A canonicidade de linking sintático/semântico}

A ênfase desta pesquisa será dada à influência do fator canonicidade de linking sintático/semântico na fase de elaboração de proposições. 
Com relação à canonicidade de linking sintático-semântico, CHOMSKY (1986) postula que o léxico apresenta, para cada item lexical, sua forma fonológica (som) e propriedades semânticas e sintáticas associadas a essa forma. Sendo assim, um item lexical, normalmente, seleciona uma categoria semântica e então essa categoria semântica seleciona uma categoria sintática que é a realização estrutural canônica (em inglês, CSR - canonical structural realization) desse item lexical. Portanto, em algumas sentenças as funções semânticas corresponderiam diretamente às suas funções gramaticais, como por exemplo, um sujeito que funciona como agente, um objeto direto que funciona como o objeto afetado pela ação, um objeto indireto que é o recebedor dos efeitos da ação, um predicativo que é um atributo, etc. Exemplificando:

a) O enfermeiro fecha os olhos da paciente. (Enfermeiro funciona como o sujeito gramatical e tem o papel semântico de agente, de causador do evento fechar. Olhos funciona gramaticalmente como objeto direto ao mesmo tempo que é, no nível semântico, o objeto afetado pela ação de fechar).

Nesta pesquisa, enfocou-se apenas a correspondência canônica/ não-canônica entre papéis temáticos e estruturas sintáticas quando foi manifesta nos sujeitos, objetos diretos e sintagmas preposicionados.

\subsubsection{Outros fatores analisados}

\subsubsection{A capacidade de processamento de informações}

Para que o leitor compreenda um texto, ele deve manter uma representação da informação prévia bem como computar as relações necessárias na seqüência do input (TOMITCH, 1996: 72). Por isso, a hipótese formulada por esta pesquisa é a de que se as relações a serem estabelecidas forem canônicas (linking sintático-semântico), o texto será mais facilmente processado. 


\subsubsection{O conhecimento prévio do leitor}

Sabe-se que, normalmente, a compreensão de um texto é um processo que se caracteriza pela utilização de conhecimento prévio, portanto, esse fator é de suma importância na leitura, pois ele oferece subsídios à compreensão. Prevê-se que, se os leitores tiverem mais conhecimento prévio sobre o assunto, poderão ler o texto com maior desenvoltura.

\section{METODOLOGIA}

\subsection{Método de coleta de dados}

\subsubsection{Sujeitos (leitores)}

Participaram desta pesquisa trinta e cinco alunas (com faixa etária variando de 17 a 37 anos) do terceiro ano de Magistério de uma escola estadual situada em Conselheiro Lafaiete-MG.

Inicialmente, as alunas submeteram-se a um pré-teste, para que se pudesse verificar o grau de conhecimento dessas leitoras sobre os assuntos abordados pelos textos. Num segundo momento, as leitoras foram classificadas de acordo com sua capacidade de processamento. Para tal classificação, foi feito um estudo preliminar individual para a medida de extensão de memória de trabalho, envolvendo as mesmas leitoras.

\subsubsection{Materiais}

No teste preliminar de verificação de conhecimento prévio das leitoras, foram utilizadas duas folhas, nas quais pediu-se para que as alunas escrevessem tudo o que sabiam sobre o funcionamento de um tomógrafo e funcionamento de uma lavadora de roupas/ tanquinho.

No segundo pré-teste (classificação da capacidade de processamento), foram utilizadas fichas de papel contendo frases a serem lidas pelas alunas. A pesquisadora utilizou, para cada leitora, uma tabela na qual eram registrados os resultados desse teste. 
No experimento principal, cada leitora teve como estímulo dois textos procedimentais (ou seja, textos cuja estrutura é formada por partes e subpartes de um processo) inéditos para elas. Um texto tratava de um assunto desconhecido por todas (o funcionamento de um tomógrafo) e o outro texto tratava de um assunto mais familiar, do qual elas tinham conhecimento prévio (o funcionamento de uma lavadora de roupas/tanquinho).

Cada um desses dois textos (sobre o tomógrafo e sobre a lavadora/tanquinho) foi transformado numa versão canônica e outra não-canônica, em relação às funções sintáticas de sujeito, objeto direto e sintagma preposicionado.

\subsubsection{Tarefas}

Os grupos realizaram as seguintes tarefas: o GRUPO 1 leu, primeiramente, o texto sobre o tomógrafo na versão canônica (TC) e o reproduziu e, em seguida, leu o texto sobre a lavadora de roupas na versão não-canônica (LNC), reproduzindo-o também. O GRUPO 2 leu e reproduziu os mesmos textos do GRUPO 1, porém numa ordem de leitura invertida (LNC-TC). O GRUPO 3 leu o texto sobre o tomógrafo na versão não-canônica (TNC) e o reproduziu e, a seguir, leu o texto sobre a lavadora na versão canônica (LC), reproduzindo-o posteriormente. O GRUPO 4 leu e reproduziu os mesmos textos do GRUPO 3, porém numa ordem de leitura invertida. As reproduções foram feitas imediatamente após a leitura de cada texto.

\subsubsection{Procedimentos e roteiro}

No teste de verificação de conhecimento prévio, feito com todas as alunas ao mesmo tempo, foi pedido que elas escrevessem tudo o que sabiam sobre o funcionamento de um tomógrafo e de uma lavadora de roupas/tanquinho.

Nesse pré-teste, as alunas leram uma série de fichas contendo conjuntos de frases. Em cada série de três fichas, paravam e diziam em voz alta as últimas palavras de cada frase lida. 
No experimento principal, todas as leitoras foram colocadas na mesma sala e a turma dividida em quatro grupos. Após as instruções orais, as alunas leram um dos textos procedimentais, conforme o grupo a que pertenciam, e para essa tarefa o tempo disponível foi de dez minutos. Depois de executada essa primeira etapa do experimento, as folhas contendo o texto original foram recolhidas e, em seguida, as leitoras reproduziram o que conseguiram se lembrar do texto lido. Depois de lerem e reproduzirem o primeiro texto, receberam o segundo texto conforme o grupo a que pertenciam, e os mesmos procedimentos foram utilizados na leitura e reprodução desse segundo texto.

\subsubsection{Contexto}

A própria sala de aula das alunas.

\subsection{Métodos de análise de dados}

No teste de verificação de conhecimento prévio, pôde-se avaliar a familiaridade/não familiaridade das leitoras com relação aos temas propostos, através da contagem de proposições construídas para um ou outro tema. No teste preliminar para classificação da capacidade de processamento, a medida de capacidade de processamento das alunas foi avaliada até o ponto em que elas conseguiram se lembrar corretamente das últimas palavras das frases.

$\mathrm{Na}$ análise dos dados do experimento principal, contabilizouse a quantidade de informações que as leitoras conseguiram reproduzir do texto original, estabelecendo-se graus de processamento: reprodução (R), reprodução com inferência (RI) ou inferência (I). Assim, uma proposição idêntica à do texto original foi considerada (R); uma proposição com algumas modificações do texto original foi considerada (RI) e proposições totalmente modificadas foram consideradas (I). 


\section{Exs.:}

Exemplo de proposições reproduzidas $(\mathrm{R})$

\begin{tabular}{|c|l|}
\hline Texto original & \multicolumn{1}{|c|}{ Texto da aluna } \\
\hline $\begin{array}{c}\text { Instrução sobre instalação e uso da } \\
\text { da Lavamax e do tanquinho Suggar. }\end{array}$ & $\begin{array}{l}\text { Instrução sobre instalação do } \\
\text { tanquinho Suggar. }\end{array}$ \\
\hline
\end{tabular}

Exemplo de proposições reproduzidas com inferência (RI)

\begin{tabular}{|c|l|}
\hline \multicolumn{1}{|c|}{ Texto original } & \multicolumn{1}{|c|}{ Texto da aluna } \\
\hline Você mesmo instala essas máquinas. & $\begin{array}{l}\text { Você mesmo pode instalar em sua } \\
\text { casa. }\end{array}$ \\
\hline
\end{tabular}

Exemplo de proposições inferidas (I)

\begin{tabular}{|l|l|}
\hline \multicolumn{1}{|c|}{ Texto original } & \multicolumn{1}{c|}{ Texto da aluna } \\
\hline $\begin{array}{l}\text { Coloque água até chegar ao nível } \\
\text { indicado na cuba. }\end{array}$ & E deixar a água encher a cuba. \\
\hline
\end{tabular}

Depois de arranjados os dados, eles foram lançados no programa SYSTAT (WILKINSON, 1988), para serem submetidos à Análise Multivariada de Variância (MANOVA).

\section{RESULTADOS}

Os resultados revelaram semelhanças e diferenças no processamento dos objetos diretos, sujeitos e sintagmas preposicionados. Percebeu-se uma maior simetria no processamento dos objetos diretos e sujeitos em comparação com os sintagmas preposicionados.

Pelos resultados, observa-se que os sujeitos sintáticos canônicos conduzem a uma interpretação mais literal do texto, enquanto os não-canônicos levam a maiores modificações no texto. 


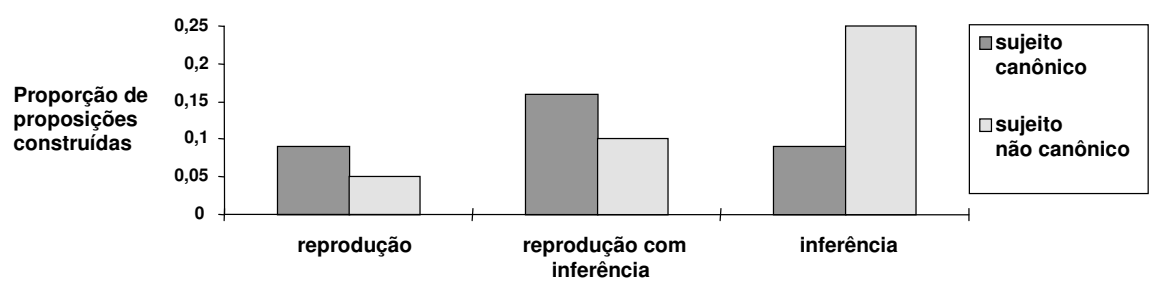

Tipos de processamento

GRÁFICO 1. Efeitos da canonicidade $\mathrm{x}$ tipo de processamento dos sujeitos

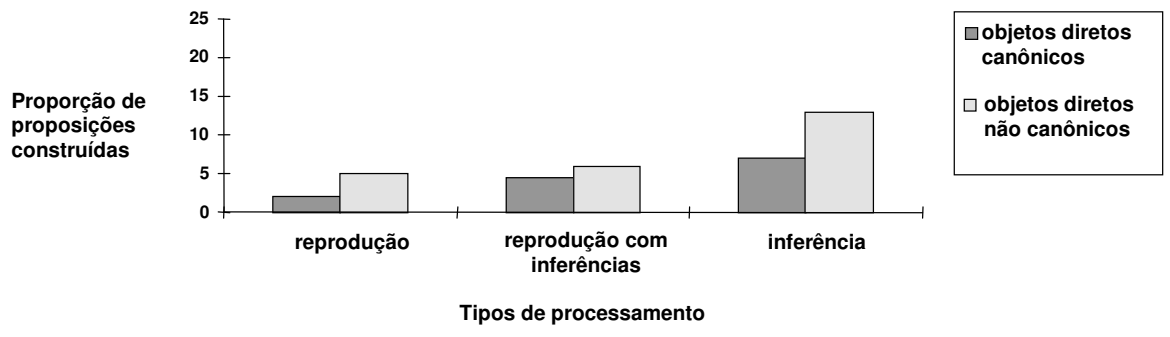

GRÁFICO 2. Efeitos da canonicidade $x$ texto $x$ tipo de processamento dos objetos diretos
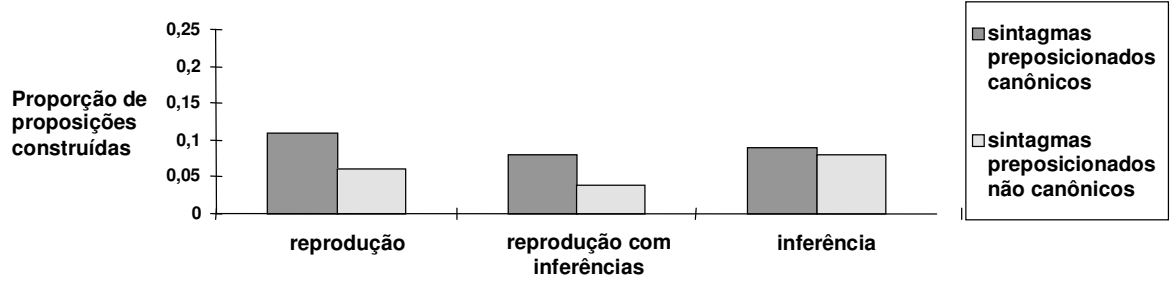

Tipos de processamento

GRÁFICO 3. Efeitos da canonicidade $x$ tipo de processamento dos sintagmas preposicionados

Em se tratando dos objetos diretos, verifica-se que quanto menos o leitor sabe sobre o assunto, mais alterações no texto ele realiza, compreendendo mais o texto quando os objetos diretos são 
canônicos. Os sintagmas preposicionados canônicos, por sua vez, favoreceram a compreensão dos textos em todos os tipos de processamento.

Os resultados, de modo geral, sugeriram que:

a) a canonicidade exerce efeito sistemático tanto nos sujeitos como objetos diretos e sintagmas preposicionados.

b) os efeitos da interação da canonicidade com o tipo de texto não foram percebidos com relação aos sintagmas preposicionados e, no detalhamento dessa interação, não se pôde perceber sua influência nos sujeitos.

c) ao analisar o efeito conjunto da canonicidade com o tipo de texto e a ordem de canonicidade, observou-se a inexistência de efeitos sistemáticos dessa interação nos sujeitos e objetos diretos.

d) os efeitos da interação canonicidade, capacidade de processamento e texto só puderam ser percebidos nos objetos diretos.

\section{DISCUSSÃO}

\subsection{Contribuições teóricas}

Pôde-se perceber que os sujeitos sintáticos e os objetos diretos compartilham algumas características (diferentes dos sintagmas preposicionados, em sua maioria), já que o processamento dessas estruturas mostrou-se bastante semelhante.

Ao considerar essas questões, buscou-se contribuir com um detalhamento do suporte teórico que sirva como subsídio para a elaboração de questionamentos mais precisos e específicos sobre o processamento dos objetos diretos, sujeitos e sintagmas preposicionados.

\subsection{Contribuições empíricas}

Nesta pesquisa, ofereceram-se dados inéditos, em português, sobre: 
a) o processamento na leitura - um estudo mais refinado e menos intuitivo do processo;

b) como os leitores lidam com a canonicidade de linking sintáticosemântico dos objetos diretos, sujeitos e sintagmas preposicionados ao construírem significados para os textos.

A principal contribuição empírica desta pesquisa, portanto, reside na especificidade oferecida pelos dados alcançados.

\subsection{Contribuições metodológicas}

Através desta pesquisa, evidenciou-se que o número de proposições construídas a partir de um texto original é um bom índice dos processos realizados pelo leitor durante a leitura. Foi igualmente observado que o teste de extensão de capacidade de leitura é um instrumento eficaz quando se pretende classificar a capacidade de processamento dos leitores.

\subsection{Contribuiç̧ões práticas}

Este trabalho pode contribuir para a prática escolar ao funcionar como uma fonte de pesquisa no sentido de saber o que facilita ou dificulta a interpretação dos sujeitos, objetos diretos e sintagmas preposicionados, ou seja, ao conhecer os efeitos da canonicidade nesses constituintes, os professores poderão selecionar com mais critério os textos a serem trabalhados com os alunos.

\subsection{Considerações finais}

O desmembramento dos processos envolvidos na leitura parece ser de suma importância se se pretende realmente compreender como eles se desenvolvem na cabeça dos leitores.

Pesquisas que se ocupem dos processos mentais realizados pelo leitor parecem indiciar avanços no estudo da leitura e, ao fornecerem uma visão mais abrangente do processo, podem subsidiar soluções mais eficazes para a prática escolar. 


\section{REFERÊNCIAS BIBLIOGRÁFICAS}

CHOMSKY, Noam. Konwledge of language: its nature, origin and use. New York: Praeger Publishers, 1986.

FODOR, Jerry A. The Modularity of Mind. Cambridge, MA: Mit Press, 1983. 129p.

OUHALLA, Jamal. Introducing Transformational Grammar: from rules to principles and parameters. New York: Jamal Ouhalla, 1994. 238p.

PERINI, Mário A. Gramática descritiva do português. São Paulo: Ática, 1996. p.71-90.

WILKINSON, L. Systat for Windows. Version 5. 1988. 


\section{ANEXO A}

\section{INSTRUÇÕES SOBRE A INSTALAÇÃO E USO DA LAVAMAX E DO TANQUINHO SUGGAR}

\section{(Texto com linking sintático-semântico canônico)}

As lavadoras comuns estragam as roupas constantemente. $\mathrm{Na}$ Lavadora de roupas Lavamax e no Tanquinho Suggar, um turbilhão de água molha as fibras do tecido e você, com um sabão, retira a sujeira. Com uma estrutura simples, a Lavamax e o Tanquinho Suggar lavam tão bem quanto qualquer máquina sofisticada. A ferrugem não consome as partes plásticas em contato com a água.

Você mesmo instala essas máquinas: coloque-as em um local seco e protegido. A seguir, desloque o indicador de voltagem do próprio aparelho para a posição correspondente à voltagem da rede de sua casa. Depois da verificação da voltagem, conecte a mangueira mais fina, localizada na parte posterior da máquina, na torneira. Posicione a mangueira grossa, puxe-a de dentro da máquina e coloque-a no ralo. Nivele bem a Lavamax ou o Tanquinho Suggar com os quatro pés no piso. Posteriormente, ligue as máquinas em uma tomada elétrica em boas condições, sem o uso de extensões ou benjamins.

Para a lavagem das roupas, feche o ralo interno da cuba da Lavamax ou do Tanquinho Suggar com a tampa. A seguir, abra a torneira, coloque água até chegar ao nível indicado na cuba e ligue o interruptor do painel. Coloque duas a três colheres de sopa de sabão em pó na água e mergulhe as roupas. A máquina tira a sujeira durante dez minutos e, posteriormente, tira o sabão.

Para tirar o sabão das roupas, desligue a máquina, e coloque a mangueira mais grossa (saída de água) no ralo. Retire, manualmente, a tampa de saída para você tirar a água e recoloque a tampa novamente. Ponha água de novo na Lavamax ou no Tanquinho Suggar até o nível marcado na cuba. Ligue a máquina por mais cinco minutos para que ela tire o sabão da roupa.

Enfim, para uma boa lavagem das roupas, coloque um bom sabão em pó e ponha a roupa "de molho", sendo que a máquina tira a sujeira num tempo de dez a quarenta minutos. Assim, você limpará a sujeira de 
até quatro quilos de roupas de cada vez, desde que ponha uma quantidade de água adequada. Você mesmo liga a Lavamax e o Tanquinho Suggar e põe água manualmente. Você também abrirá e fechará a torneira. Para a boa conservação das máquinas, limpe a sujeira do Tanquinho Suggar ou da Lavadora Lavamax com água morna, sabão neutro, pano ou esponja.

\section{INSTRUÇÕES SOBRE A INSTALAÇÃO E USO DA LAVAMAX E DO TANQUINHO SUGGAR}

\section{(Texto com linking sintático-semântico não-canônico)}

As roupas desmancham constantemente nas lavadoras comuns. $\mathrm{Na}$ Lavadora de roupas Lavamax e no Tanquinho Suggar, as fibras do tecido são molhadas por um turbilhão de água, com um sabão, a sujeira desaparece, e assim suas roupas permanecem perfeitas. Uma estrutura simples compõe a Lavamax e o Tanquinho Suggar, mas a lavagem é tão boa quanto de qualquer máquina sofisticada. As partes plásticas em contato com a água não enferrujam.

Essas máquinas são instaladas por você: elas devem ser colocadas em um local seco e protegido. A seguir, verifique se a voltagem da Lavamax ou do Tanquinho Suggar (observar no indicador de voltagem do próprio aparelho) é a mesma da rede de sua casa. Depois de você observar a voltagem, a mangueira mais fina, localizada na parte posterior da máquina, deve ser conectada na torneira. A mangueira grossa deve ser posicionada, puxada de dentro da máquina e colocada no ralo. A Lavamax ou o Tanquinho Suggar devem ser bem apoiados e nivelados com os quatro pés no piso. Posteriormente, o fio da lavadora Lavamax ou do Tanquinho Suggar deve ser ligado numa tomada elétrica que suporte a voltagem, sem o uso de extensões ou benjamins.

Para a lavagem das roupas, o ralo interno da cuba da Lavamax ou do Tanquinho Suggar deve ser tampado. A seguir, a água encherá a cuba até chegar ao nível indicado e o interruptor do painel deve ser ligado. A água deve conter de duas a três colheres de sopa de sabão em pó e as roupas devem ser mergulhadas. Durante dez minutos, as roupas serão lavadas, para posterior enxagüe.

Para o enxagüe das roupas, a máquina deve ser desligada, e o ralo deve conter a mangueira mais grossa (saída de água). A tampa de saída 
deve ser retirada para a água se esgotar e o ralo deve ser tampado de novo. Novamente, a Lavamax ou o Tanquinho Suggar conterão água até o nível marcado na cuba. Na tomada elétrica, o fio da máquina deve ser ligado por mais cinco minutos para que a roupa esteja enxagüada.

Enfim, a boa lavagem das roupas compreende um bom sabão em pó e o tempo em que a roupa ficou "de molho", sendo que a máquina lava as roupas num tempo de dez a quarenta minutos. Assim, até quatro quilos de roupas serão lavadas de cada vez, desde que você observe sempre o nível de água adequado. Você controla o funcionamento e o nível de água da Lavamax e do Tanquinho Suggar manualmente. A torneira será aberta e fechada por você. Para a limpeza das máquinas, utilize água morna, sabão neutro, pano ou esponja. Essa forma de limpeza contribui para a conservação da máquinas.

\section{ANEXO B}

\section{O FUNCIONAMENTO DE UM TOMÓGRAFO}

\section{(Texto com linking sintático-semântico canônico)}

Uma paciente fala com seu médico sobre suas dores de cabeça, fraqueza nos braços e náusea. O médico trata os sintomas como indícios de um tumor no cérebro da mulher, mas como coletar informações sobre esse tumor sem lesar a paciente? Para isso, os médicos trabalham com um aparelho - o tomógrafo PET - da seguinte maneira:

Inicialmente, o médico deita a paciente de costas. A seguir, um enfermeiro fecha seus olhos com gaze e prende sua cabeça com alfinetes plásticos. Finalmente, o enfermeiro coloca a cabeça da paciente dentro de uma máquina em forma de anel e injeta uma solução radioativa. Quando o cíclotron lança prótons para dentro do núcleo dos átomos de carbono do tecido da paciente, estes emitem pósitrons. O pósitron extra instabiliza os átomos, mas somente por meia hora. O médico injeta esses átomos instáveis com a glucose na nuca da paciente.

Depois dessa injeção, o médico coleta informações sobre a paciente com o tomógrafo. Os detectores desse aparelho captam raios gama. O médico coloca a cabeça da paciente no centro do tomógrafo por causa do seu formato de anel. Os átomos instáveis ejetam pósitrons, estabilizando 
os átomos novamente. Os elétrons no tecido da paciente modificam os pósitrons e cada um emite dois raios gama (fenômeno de aniquilação). Quando os raios gama alteram dois detectores simultaneamente, o tomógrafo envia um código ao computador. Através de um tubo, esses detectores captam raios somente pela frente. Assim, cada par desses detectores recolhe informações sobre uma pequena área do tecido. O tomógrafo coleta os códigos e os detectores de origem.

Depois de o médico coletar informações sobre a paciente com o tomógrafo, o computador reorganiza os dados e apresenta-os como uma imagem da região do cérebro. Um programa coleta os códigos que todos os pares de detectores enviaram, e então apresenta ao médico o número de raios gama que cada região do cérebro emitiu. O computador apresenta a imagem de uma seção cerebral como algumas áreas coloridas na tela.

Para a observação dos tumores, os médicos trabalham com a premissa de que os tumores emitem mais luz, consomem mais energia que o tecido normal e que eles tiram essa energia da glucose. Assim, o médico coleta dados necessários e não abre o cérebro, por isso não lesa a paciente.

\section{O FUNCIONAMENTO DE UM TOMÓGRAFO}

\section{(Texto com linking sintático-semântico não-canônico)}

Uma paciente informa seu médico sobre suas dores de cabeça, fraqueza nos braços e náusea. O médico vê os sintomas como indícios de um tumor no cérebro da mulher, mas como examinar esse tumor sem provocar lesões no cérebro da paciente? Para isso, os médicos usam um aparelho - o tomógrafo PET - da seguinte maneira:

Inicialmente, a paciente deita de costas. A seguir, seus olhos são fechados com gaze e sua cabeça é presa com alfinetes plásticos. Finalmente, a cabeça da paciente é colocada dentro de uma máquina em forma de anel e recebe uma injeção de uma solução radioativa. Pósitrons são emitidos pelos prótons quando estes são lançados para dentro do núcleo dos átomos de carbono do tecido da paciente por um cíclotron. Os átomos são instabilizados por este pósitron extra, mas somente por meia hora. A paciente recebe, na nuca, uma injeção desses átomos instáveis com a glucose.

Depois dessa injeção, o médico examina a paciente com o tomógrafo. Os detectores desse aparelho são sensíveis aos raios gama. A cabeça 
da paciente é colocada no centro do tomógrafo por causa do seu formato de anel. Pósitrons são ejetados pelos átomos instáveis, estabilizando os átomos novamente. Os elétrons no tecido da paciente acertam os pósitrons e dois raios gama procedem de cada deles (fenômeno de aniquilação). Quando os raios gama alcançam dois detectores simultaneamente, o computador recebe um sinal do tomógrafo. Através de um tubo, esses detectores percebem raios somente pela frente. Assim, cada par desses detectores examina uma pequena área do tecido. O tomógrafo recebe os sinais e os detectores de origem.

Depois de o médico examinar a paciente com o tomógrafo, o computador verifica os dados, representando-os como uma imagem da região do cérebro. Um programa examina os sinais que foram enviados por todos os pares de detectores, e então observa o número de raios gama que foi emitido por cada região do cérebro. O computador constrói a imagem de uma seção cerebral como algumas áreas coloridas na tela.

Para a observação dos tumores, os médicos sabem da premissa de que os tumores brilham mais, apresentam maior consumo de energia que o tecido normal e que essa energia procede da glucose. Assim, o médico verifica dados necessários sem a abertura do cérebro, por isso a paciente não sofre lesões. 